\title{
Landscape-level naturalness of conservation easements in a mixed-use matrix
}

\author{
Nakisha Fouch (1D) - Robert F. Baldwin (D) Patrick Gerard • Caitlin Dyckman • \\ David M. Theobald
}

Received: 26 September 2018/ Accepted: 1 July 2019/Published online: 8 July 2019

(C) The Author(s) 2019

\begin{abstract}
Context With underrepresentation of habitats in publicly protected areas, attention has focused on the function of alternative land conservation mechanisms. Private conservation easements (CEs) have proliferated in the United States, yet assessing landscape-level function is confounded by varying extent, resolution, and temporal scale.

Objectives We developed and tested an assessment tool to evaluate interacting spatial, social, and environmental attributes of easements relative to the degree of human modification (HM). We hypothesized that on both private and public conservation properties HM would be lower than on non-conserved
\end{abstract}

Electronic supplementary material The online version of this article (https://doi.org/10.1007/s10980-019-00867-y) contains supplementary material, which is available to authorized users.

N. Fouch $(\bowtie)$

Department of Forestry and Environmental Conservation, Clemson University, 118A Lehotsky Hall, Clemson,

SC 29634, USA

e-mail:nfouch@clemson.edu

R. F. Baldwin

Department of Forestry and Environmental Conservation, Clemson University, 261 Lehotsky Hall, Clemson,

SC 29634, USA

P. Gerard

Department of Mathematical Sciences, Clemson

University, O-114 Martin Hall, Clemson, SC 29634, USA parcels, and that for fine-scale features (most CEs), the level of HM would be driven by the variables used to create the coarser scale HM measure.

Methods Variation in HM between private, public, and non-conserved was tested via pairwise parcel sampling. Composition was evaluated using multiple geographic bounds and edge characteristics. We assessed both environmental and social predictors using multinomial logistic regression.

Results Privately conserved lands did not differ significantly from non-conserved lands. Publicly conserved lands had lower HM than both privately conserved and non-conserved lands. Edge contrast was similar between private and matched non-conserved patches. The level of HM was not driven by distance to roads, or by elevation in this mixed-use setting.

\author{
C. Dyckman \\ Department of City Planning and Real Estate \\ Development, Clemson University, 2-319 Lee Hall, \\ Clemson, SC 29634, USA \\ D. M. Theobald \\ Conservation Science Partners, 5 Old Town Square Suite \\ 205, Fort Collins, CO 80524, USA
}


Conclusions Variation in tests for differences, land characteristics, and HM variables confirmed the significantly lower HM of publicly protected lands, and opens the question as to naturalness of easements in some contexts. CEs in this location may be representative of the mixed rural-forested landscape instead of more natural land cover.

Keywords Conservation easement · Human modification · Private land conservation - Land-use change $\cdot$ Protected-area planning

\section{Introduction}

In an epoch characterized by human dominance of ecosystems, landscape structure and function often result from accumulated land-use decisions including where and what to conserve. The social context results in observable changes in landscapes including land uses with their attendant patterns of human occupation and distribution and composition and condition of conserved areas (Theobald et al. 1997; DeFries et al. 2004). Although large reserves owned and managed by governments are the backbone of conservation, an array of non-traditional approaches, often at more local scales, may be necessary to improve landscape matrix quality and to build functional components of a multi-scale reserve system (Baldwin and Demaynadier 2009; Zeller et al. 2012). Among such efforts are community-owned and managed areas, private reserves, shifting reserves and leasebacks, covenants, multiple use zoning, and severance of development rights (Porter-Bolland et al. 2012; Randolph 2012; Iftekhar et al. 2014).

Conservation easements (CEs) are the most rapidly increasing form of land conservation in the US. These proliferated during the last 4 decades across varying land uses (Land Trust Alliance 2015). Advantages include maintaining private land ownership, preserving autonomy, and leveraging incentive-based, voluntary conservation action (Merenlender et al. 2004). $\mathrm{CE}$ incentives have been placed at federal, state, and local levels and are considered expedient relative to fee simple sales and other conservation tools that are more costly or complicated to administer (Merenlender et al. 2004). CEs are characterized as a private land conservation mechanism supported by tax law.
Federal laws mandate that a $\mathrm{CE}$ that qualifies for deduction maintain specific characteristics, i.e., meeting one or more specific charitable purposes, offering perpetual land conservation, and donation to a qualified holder (Korngold 2006; McLaughlin and Machlis 2008; McLaughlin and Weeks 2009). Easements are established and monitored by land conservancies, which are monitored by The Land Trust Alliance (LTA) in the US. LTA conducts a census approximately every 5 years to inventory numbers of organizations, acreage, and land trust objectives. The 2015 census reported 1700 organizations in 2005 and 2010 but fewer (1350) in 2015 due to a change in designation, in addition to typical industry decline. LTA reported an increase in acreage from 6 million in 2005 to 16.5 million in 2015 (Land Trust Alliance 2015).

Given varying land trust objectives and accepted CE types and despite the increased establishment of CEs, the effort to monitor and assess CEs and their functions is widely reported to be inadequate (Merenlender et al. 2004; Kiesecker et al. 2007; Rissman et al. 2007; Rissman and Merenlender 2008). To this point, studies are lacking a method for which to empirically examine conservation of conserved lands, generally, and as a result it is unclear what type of and the extent to which private conservation initiatives are realizing a conservation effect (Merenlender et al. 2004; Nolte 2018). Studies thus far suggest that at the landscape scale, CEs complement publicly protected areas and contribute to connectivity but underrepresent the diversity of ecosystems (Baldwin and Leonard 2015; Graves et al. 2019). Compared to other conservation lands, easements protect different subsets of ecosystems, are more likely to protect agricultural lands, and contribute to open space connectivity (Rissman and Merenlender 2008). Yet no study thus far has examined composition of easements relative to random non-conserved lands and public protected areas using a remote measure of naturalness or human modification (HM). The laws governing CEs are considered to be intentionally vague and in need of oversight (Hilty et al. 2006). Consequently, easement law can be applied on an ad hoc or opportunistic basis in the acquisition and placement of CEs, which can produce adverse impacts on the stated mission or conservation purpose of the managing land trust (Merenlender et al. 2004). Given the increasing conservation importance of privately conserved lands and the need for rapid 
assessment to meet the terms of establishment and to guide policy, tools are needed to assess CE composition and potential benefit at the landscape-scale.

Effective analysis across protected areas requires complete and accurate geospatial databases. Protected areas databases for public areas are relatively complete, yet obtaining accurate data on distribution of conservation easements, especially smaller parcels, remains a challenge (Clements et al. 2018). With the tension between maintaining landowners' privacy, assessment through systematic conservation effectiveness, and monitoring and enforcing through governing bodies and land trust oversight, there is incomplete tracking and mapping of easements and other private conservation properties (Rissman et al. 2017). The National Conservation Easement Database (NCED) is the only source of spatial and tabular data compiled over an extensive area in the United States. However the NCED acknowledges incompleteness, as we validate here (Methods). Given this, other county sources were used to supplement.

We applied the concept of naturalness to evaluate lands being conserved privately. We grounded our assessment in the notion that mapped measures of ecological integrity can be used as a surrogate for other aspects of biodiversity (Parrish et al. 2003; Theobald 2010; McGarigal et al. 2018). Mapped measures that estimate "integrity" are useful in landscape ecology and conservation when accurate field-based data are missing or incomplete. Such models have included the Human Footprint, Index of Ecological Integrity, Marginal Biodiversity Value from InVEST, and degree of HM (Sanderson et al. 2002; Nelson et al. Nelson E 2009; Theobald 2010, 2013; McGarigal et al. 2018). We note that conservation projects are not always undertaken to achieve naturalness goals or HM goals and a plethora of reasons underlie the legal establishment of easements (Gustanski and Squires 2000; Merenlender et al. 2004; Kabii and Horwitz 2006; Rissman et al. 2007). Yet in seeking remote measures to enable assessment of composition and condition at the landscape scale, it is often necessary to adopt generalized surrogates (Jennings 2000; Groves et al. 2002; Sanderson et al. 2002; Nelson et al. 2009; Theobald 2013). These provide one level of information but should not be considered a full replacement for field-based measures or measures specifically tied to terms of the establishment. There is no one "right" model; each fits the needs of the developers and the users. For our purposes, the HM estimate allowed us to place the composition of CEs within a range of naturalness and within the landscape context thereby creating opportunities to integrate social and ecological values through policy-relevant science.

In the context of conservation research, naturalness is typically defined as that which can be measured as not having been modified or transformed by humans (Hunter Jr 1996; Angermeier 2000). Measurement of modification typically involves creating an index based on a spatial algorithm using multiple indicators and results in a gradient from natural to artificial (Machado 2004), and approaches have varied over the years (Hannah et al. 1995; Sanderson et al. 2002; Leu et al. 2008; Woolmer et al. 2008; Theobald 2013). A version of this gradient is constructed based on the theory of landscape classification of urban-wild gradients (Theobald 2003, 2004), and multi-scale influences (Theobald 2013). The degree of HM is an empirically-based model estimate of ecological integrity intended for landscape assessment. It uses measures of geospatial features seen as stressors and then applies fuzzy sum methods to combine effects into one measure representing HM of the landscape (Theobald 2013). Stressors include land use, land cover, and presence, use, and distance from roads. The fuzzy sum minimizes bias associated with non-independence between stressors, assumes that the influence of one threat decreases as influences from other threats intersect, and that locations with overlapping stressors tend toward higher values (Theobald 2013). The HM is bounded between 0.0 and 1.0, approaching 1.0 as human impact increases and the US average is 0.375 (Theobald 2013). HM followed other ecological scoring systems and addresses two improvements (Gardner and Urban 2007; Riitters et al. 2009; Theobald 2010, 2013), (1) the importance of proportion of land cover (Gardner et al. 1987; Gardner and Urban 2007) as a basis for assessment of landscape change (Riitters et al. 2009), and (2) the addition of an estimate that has a direct physical basis supplied through decision theory-based methods for accountable indicators (Hajkowicz and Collins 2007).

To use mapped naturalness as a means of assessing composition of conservation easements, we used its exact inverse, the degree of HM (Theobald 2010, 2013). We chose HM because it estimates both the proportion of natural land cover and the effects of stressors such as varying land uses and the proximity 
to, and density of roads (Theobald 2013). Also, the $\mathrm{HM}$ incorporates effects across multiple scales into a cell-level estimate of the landscape-level degree of HM so that effects are somewhat smoothed. Importantly, our inference about function of easements based on the HM, or any single measure, is limited by the assumptions of that particular model. Our use of the HM in parcel-level data provides insight into the composition and potential conservation impact of private conservation in a mixed-use exurban-rural landscape. To better understand the measure itself, we conducted field surveys to compare observed composition with HM. Understanding the ecological and social characteristics associated with the placement and land transformation of CEs parcels can provide guidance into conservation planning (Theobald 2005; Gaston et al. 2006; Kiesecker et al. 2007; Rissman and Merenlender 2008).

Given the increased use of conservation easements as a tool for private conservation, their complement to public conservation and connectivity, and the general placement trends of publicly conserved areas, we explored the difference in composition and proximity tendencies of privately conserved lands relative to publicly conserved lands, and to random, private, nonconserved parcels using a remote measure of naturalness (HM). We hypothesized that; (1) HM is lower on both publicly and privately conserved parcels than on non-conserved parcels; (2) conserved properties are likely to be higher in elevation, farther from heavily traveled roads and urban areas, closer to water, and have a more natural proportion of land cover; and (3) variables used to derive the coarse landscape level HM (proportion of natural land cover, land use, and road intensity), will be primary predictors of HM category (low, moderate, high, and very high) across fine scale parcels. We conducted the study in southeastern Appalachia, USA, a heterogeneous mountain region with large public protected areas interspersed with mixed-use landscapes, regional cities, and within a day's drive of large urban areas.

\section{Materials and methods}

Study area

Appalachia contains some of the highest priority conservation areas in the US (Jenkins et al. 2015) and patterns of human settlement and land use that are topographically driven (Harmon et al. 1984). The study area incorporates two counties in the foothills of the southern Appalachian Mountains, Caldwell and Rutherford Counties in North Carolina. Both counties have experienced over a century of intensive land use including agriculture, textile production, and mining (Yarnell 1998). Both have diverse conservation lands including CEs, conservancy-owned preserves, and state parks and national forests (Online Resource 1).

Foothills Conservancy of North Carolina (FCNC) is the primary conservancy in the study area, conserving approximately 21,900 ha across eight counties, with approximately 17,800 ha of the conserved land transferred to public ownership (Foothills Conservancy of North Carolina 2018). FCNC practices spatial conservation planning and requires standard documentation i.e., baseline documents, management plans, and annual stewardship reports, and are accredited by the Land Trust Alliance (LTA).

We chose two counties to represent an area mixeduse in nature, where mixed-use includes a gradient ranging from rural to exurban, and exurban is defined as "semi-rural region beyond the suburbs of a city, characterized by low density... .large lot development" (Daniels 1999; Theobald 2003, 2005) (Online Resource 2). As recommended for easement studies, counties represented a variety of "conservation contexts" including more than one ecoregion, legal and political structures, social characteristics, and differing varieties of conservation instruments and activity (Kiesecker et al. 2007).

\section{Caldwell County, North Carolina}

Caldwell County is in the foothills of the Blue Ridge Mountains and has elevations ranging from 270 to $1830 \mathrm{~m}$ and includes two watersheds, the Upper Yadkin (HUC 03040101), and the Upper Catawba (HUC 03050101). It is approximately $110 \mathrm{~km}$ northwest of the large urban center of Charlotte and $140 \mathrm{~km}$ from two regional cities, Winston-Salem and Asheville, North Carolina.

Major land cover includes $70 \%$ forested, $15 \%$ developed area, $10 \%$ agricultural, and $5 \%$ grasslands (Homer et al. 2015). In 1910 there were 2548 farms in the county representing 88,220 ha, a century later reduced to 411 farms representing 13,000 ha (percent area in farmland dropped from 67 to $11.5 \%$ ) (Durand 
et al. 1913; United States Department of Agriculture 2014). Caldwell County experienced intensive land use from agriculture to the extraction of natural resources to support the textile and furniture industry in the early 20th century (Yarnell 1998). Present day Caldwell County is a tourist destination, as a portion is covered by the Blue Ridge Mountains and Pisgah National Forest, with scenic views and river access. Public and private conserved lands cover $22 \%$ of the county.

\section{Rutherford County, North Carolina}

Rutherford County is in the southwestern section of the State and is bounded on one side by South Carolina. It is a mosaic of forested mountain foothills with rolling fields and two watersheds, South Fork Catawba (HUC 03050102) and Upper Broad (HUC 03050105); unlike Caldwell County, it has not experienced the same degree of tourism.

Major land cover includes $70 \%$ forested, $15 \%$ agricultural, $15 \%$ grasslands, and 10\% developed (Homer et al. 2015). According to the 1910 agricultural census there were 3447 farms in the county representing 111,300 ha, a century later reduced to 638 farms representing 24,000 ha (percent area in farmland dropped from 79 to $14 \%$ ) (Durand et al. 1913; United States Department of Agriculture 2014). This county also experienced intensive land use over time through both agricultural use, and in the early-tomid-19th century, the mining of gold (Corbitt and North Carolina Division of Archives and History 1950; Yarnell 1998). Public and private protected lands cover $10 \%$ of the county.

Data description, acquisition, and processing

Data include conservation properties and spatial representation of protected properties and other unprotected land parcels. Conservation data were acquired through the local conservancy, FCNC, the National Conservation Easement Database (NCED) obtained in July of 2016, and NC One Map for parcel data. NCED is a public database (https://www. conservationeasement.us/), containing shapefiles for CEs across the United States. FCNC is one of many conservancies who do not upload their data into NCED. After comparing FCNC data to available NCED data, we found that the two data sets were mutually exclusive for both counties (Figs. 1 and 2). For Caldwell County the NCED did not contain any FCNC properties but did contain properties held by The Nature Conservancy (TNC), The Trust for Public Land (TPL), and the Conservation Trust for North Carolina (CTNC). The NCED results for Rutherford County showed no FCNC properties but included properties held by TNC, TPL, Carolina Mountain Land Conservancy, and the Parcolet Area Conservancy.

To evaluate hypotheses one and two across the counties (unit of analysis) we used a random sampling design in order to evaluate the null hypothesis of no significant difference in the mean of all applicable variables (Online Resource 3) within a county and across parcel type. Privately conserved parcels and random non-conserved parcels were compared by generating random points within parcel polygons with the sample size being positively proportionate in size to the area of the parcels, majority land cover being similar, and requiring a minimum inter-point distance of $90 \mathrm{~m}$ to accommodate the resolution of the HM surface. Public parcel attributes were also compared using random sample points positively proportionate to size but not via a matching pairs design, public parcel area was often unmatchable to a random nonconserved parcel. Land characteristics were generated to assist in a better understanding of the function and composition of the county landscape in context of the HM in each county. Next, hypothesis three was evaluated using a multinomial logistic regression (MNLR) given four categories of HM (low, moderate, high, and very high). MNLR allowed us to better examine drivers of each HM category given the predictors listed in Online Resource 3. Finally, a second random sample was taken from the original set of random points to field validate each applicable level of the HM for reasonableness of the HM estimate.

For both counties we generated a random sample of points from within privately conserved parcels, nonconserved parcels, and publicly conserved parcels. For each random point generated, elevation was extracted from the National Elevation Dataset (NED) (Gesch et al. 2002) (Online Resource 3). The HM estimation was used as an indicator for land transformation (Online Resource 3). Majority land cover calculated from the National Land Cover Dataset (2011) was used to match non-conserved parcels to privately protected parcels as part of the pairwise comparison 


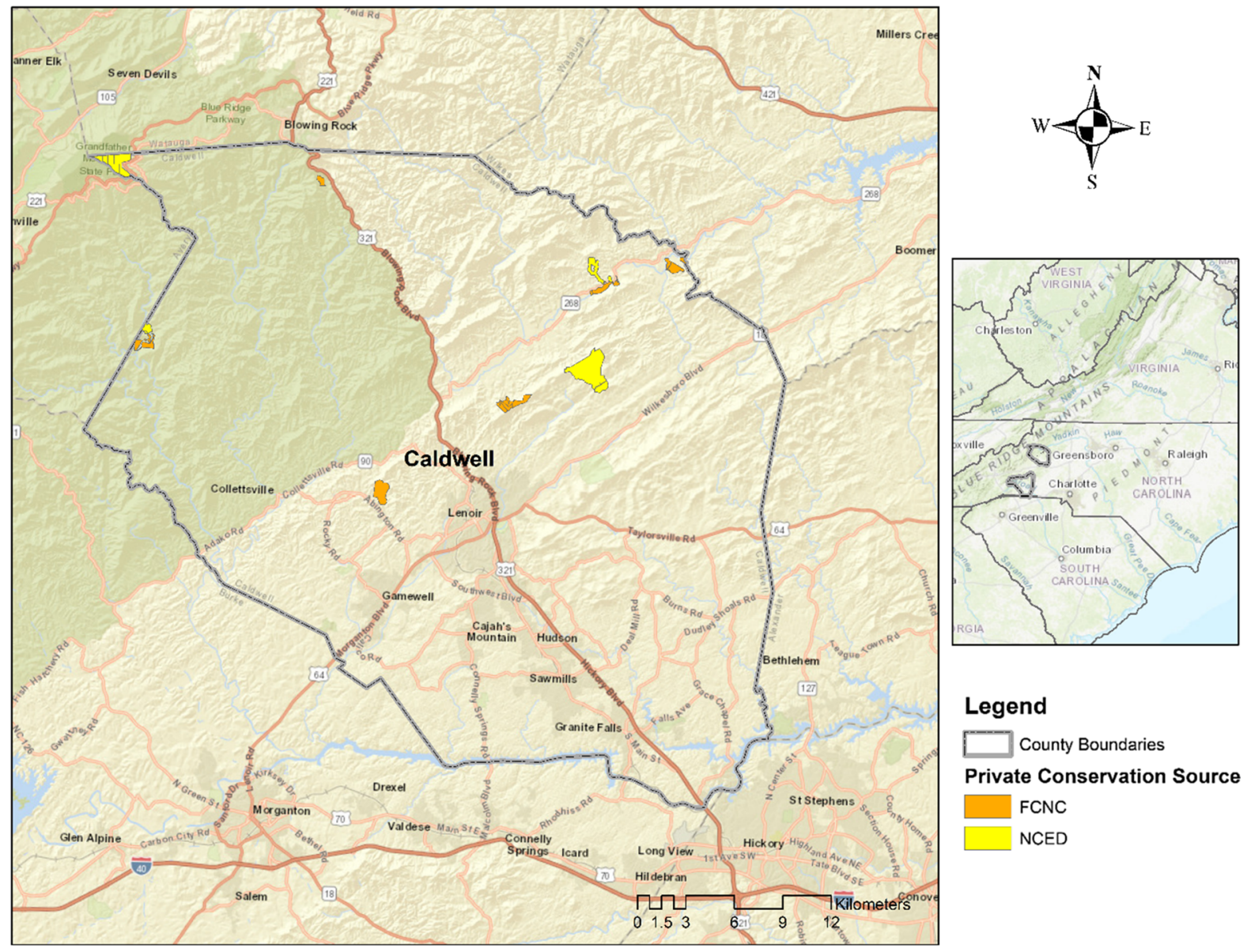

Fig. 1 Caldwell County comparison of National Conservation Easement Database and Foothills Conservancy of North Carolina private conservation properties. In Caldwell County

(Online Resource 3) and also to evaluate the proportion of natural land cover in the landscape composition. The U.S. Census American Community Survey (ACS) 5 year estimates (2011-2016) was used for income and population at the block group level (Online Resource 3). Euclidean distances were calculated between all randomly sampled points and the nearest feature for the following variables: roads, streams, urban areas, and publicly protected land (Online Resource 3).

\section{Sampling design}

Spatial data containing characteristics and location of easement and preserve properties and non-conserved parcels were combined with other geographical and social attributes, generated from literature on exurban the two sources are mutually exclusive, there is no overlap in private conservation parcels found in the two different sources

development, land transformation, and private land conservation (Theobald 2003, 2004, 2005; Kiesecker et al. 2007; Rissman et al. 2007; Jenkins et al. 2015). The study sampled all privately protected parcels; CEs and privately owned preserve parcels ( $\mathrm{N}=26$ for both counties). Using a matched-pairs statistical design approach, analogous to the matched sampling method used by Reed and Merenlender (2008) and Joppa and Pfaff (2011), privately protected parcels were matched to privately-owned, non-conserved lands based on land cover type, and the size of the parcel to maximize similarity across parcel types. High spatial autocorrelation between the location of privately protected parcels and the matched non-conserved parcel emphasizes the similarity of the parcels, making any difference in variable means specific to the treatment, i.e., protected or unprotected. Differences were tested 


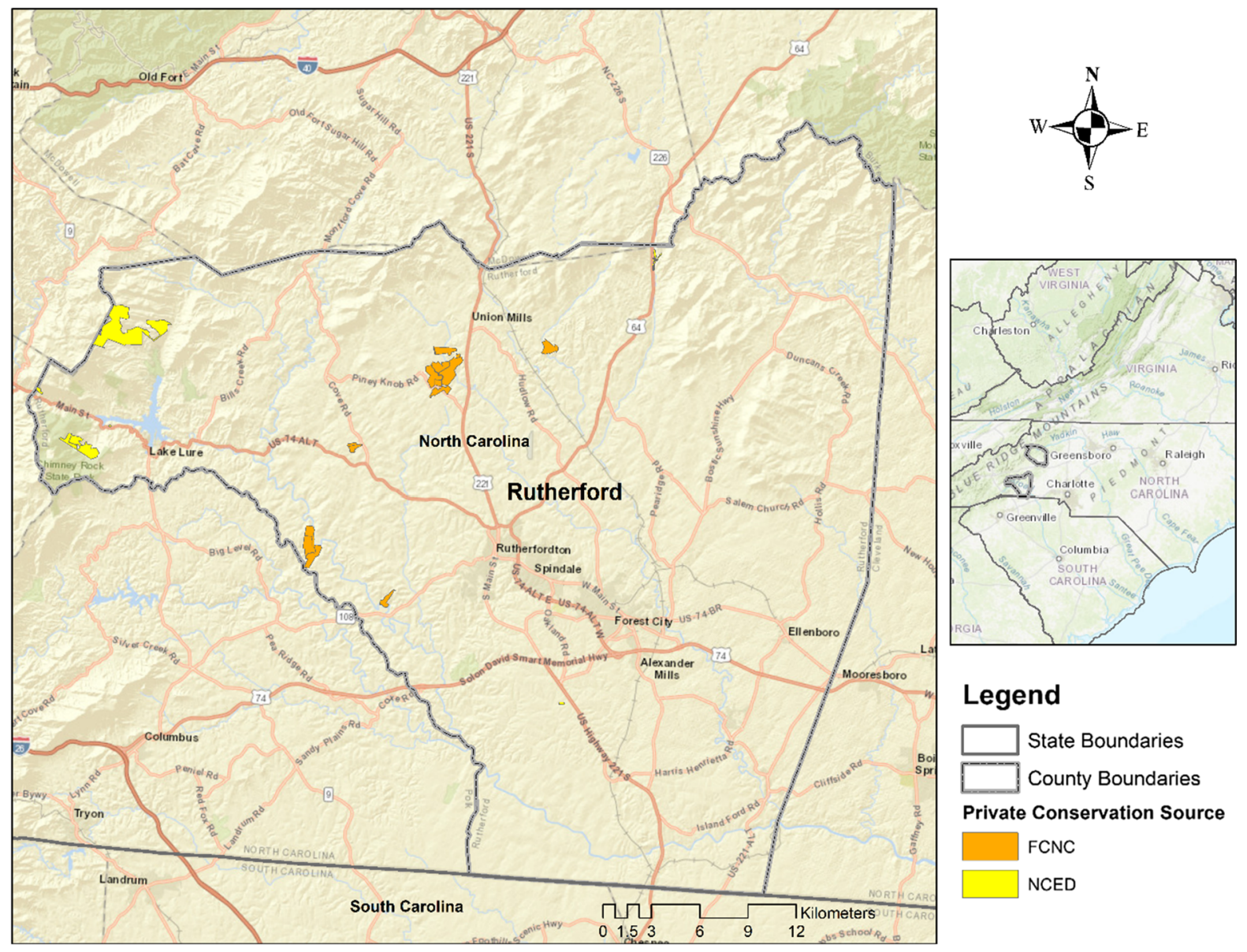

Fig. 2 Rutherford County comparison of National Conservation Easement Database and Foothills Conservancy of North Carolina private conservation properties. In Rutherford County

using a paired $t$ test, or the Wilcoxon signed rank in the case that the variables were not normally distributed. A similar, although non-matched-pairs sampling design was used to test the differences between privately owned (protected and non-protected) and publicly protected areas, due to lack of private areas of comparable public size.

\section{Landscape characteristics}

Landscape metrics were developed to analyze spatial patterns of landscapes in terms of both composition and arrangement. Matched pairs were used to evaluate the proportion of land cover categories by county and by patch classes as in private-protected, publicprotected, non-protected of which the matched parcels are a subset. A $90 \mathrm{~m}$ buffer around the private- the two sources are mutually exclusive, there is no overlap in private conservation parcels found in the two different sources

protected patches was created to better understand the land cover impacting the edges of the privateprotected patches, and chosen to accommodate the $90 \mathrm{~m}$ HM resolution. NLCD categories were collapsed to into the NLCD summary categories: developed land (NLCD land categories: 21, 22, 23, 24), agriculture (NLCD land categories: 81, 82), water (NLCD land categories: 11, 12), barren (NLCD land categories: 31 ), forest (NLCD land categories: 41, 42, 43), scrub (NLCD land categories: 52), herbaceous (NLCD land categories 71), and wetlands (NLCD land categories: 90, 95) (Homer et al. 2015), and analyzed by county and patch class. Forest cover was evaluated based on relative abundance in private conservation and unprotected parcels to gain further insight into the basis of the naturalness findings. 
To better understand the contrast between HM categories derived in the multinomial logistic regression analysis (classes) relative to patches (privately conserved parcel and their matched non-conserved parcels), we used Edge Contrast (ECON) from FRAGSTATS (McGarigal et al. 2012). ECON describes the relative contrast along the patch perimeter, and were summarized at the class and landscape level. ECON ranges from 0 to 100 , if found to be zero the landscape may consist of only one patch, or the adjacencies have been given a zero-contrast weight (McGarigal et al. 2012). A contrast weights table is required by the software and provides a means for the user to compare the similarity or difference of a class or category to one another. The contrast weights table was defined based on the classes or categories of $\mathrm{HM}$ used in the multinomial logistic regression analysis and defined in the exurban gradient presented in Theobald $(2003,2004)$ (Online Resource 4). If the maximum weight contrast is utilized between patch adjacencies the ECON will be at or near 100. Mean ECON was generated and summarized at the class and landscape level as documented in McGarigal et al. (2012). We used this metric to evaluate the level of HM edge contrast both at a landscape level for each patch type and at an HM category level for each patch type to examine how the HM varies across the landscape.

Model development, comparison, and validation

We tested HM for normal distribution and found it skewed right for both counties. Because of this, and the 0 to 1 bounding of HM, we chose a multinomial logistic regression (MNLR) to examine how the levels of HM (Online Resource 4) for privately protected conservation areas can be predicted by the explanatory variables, using a main effects approach. HM is broken into four variables (low, moderate, high, and very high) (Online Resource 4) based the literature (Theobald 2003). The low category was not found in either county.

Although MNLR has minimal assumptions, it does require independence among the dependent variable categories (HM) in addition to non-perfect separation. We tested independence using the Hausman-McFadden test and in no case was this test significant. Nonperfect separation occurs if the groups of outcomes (HM breaks) are perfectly separated by any of the predictors (Online Resource 3). This causes unrealistic coefficients to be estimated and effect sizes to be greatly exaggerated via inflated coefficients and standard error (Schwab 2002). Correlation was examined among predictors using a Pearson correlation table (predictor correlation coefficients greater than or equal to 0.6 were removed), and multicollinearity through use of the variance inflation factor (VIF) (where VIF greater than or equal to 10 signifies multicollinearity) (Online Resource 6).

A multinomial logistic regression (MNLR) was performed to model the relationship between the predictors (Online Resource 3) and membership in four HM categories (Online Resource 4). The MNLR model was built using McFadden's pseudo $\mathrm{R}^{2}$ and Akaike Information Criterion (AIC). Generally, the $\mathrm{R}^{2}$ criterion calls for the evaluation of the coefficient of multiple determination $\mathrm{R}^{2}$ in order to identify several "good" subsets of the predictor variables, that is, subsets for which $\mathrm{R}^{2}$ is high (Kutner et al. 2005). The interpretation of McFadden's pseudo $\mathrm{R}^{2}$ is slightly different and can be considerably lower than the typical coefficient of determination $\left(\mathrm{R}^{2}\right)$ (Hensher and Stopher 1979). Based on these principles, the models for each county were reduced to the best parsimonious fit. To test accuracy of the non-linear MNLR models, repeated $(\mathrm{N}=100) \mathrm{k}$-fold cross validation resampling were performed. This method randomly splits the total observations into $\mathrm{k}$ groups of approximately equal size, then fits the model with $\mathrm{k}-1$ groups and determines prediction accuracy based on the remaining group. This is then repeated so that each of the $\mathrm{k}$ groups is used to fit the model $\mathrm{k}-1$ times (Borra and Di Ciaccio 2010). This procedure was repeated 100 times to obtain the mean of the accuracy, or overall agreement rate, as well the agreement standard deviation.

Field visits and ground-truthing

A second set of random points were selected from the original set of sampled points, five points that fell into each HM category (Online Resource 4) were selected for both privately protected parcels and matched nonprotected parcel. This resulted in a total of 15 points for field evaluation, covering the three HM categories, per county. Because of the collaboration with FCNC and their landowners, access was only limited by terrain. In those cases ( $<$ three points per county) fine- 
scale Google Earth imagery was used instead. Points were evaluated in the field for land cover, land use, and land management information, both at the point and contextually (Online Resource 5). For HM, understanding the context of the point is important, since changes in HM are based not just on the land cover at the point itself, but also on particular features that are in relatively close proximity to the point e.g., urban areas, residential development, roads, and even state parks (Cole and Landres 1996; Forman and Alexander 1998; Miller and Hobbs 2000; Theobald 2003).

\section{Results}

Variations in naturalness in conserved and nonconserved lands

Hypotheses 1 and 2 For both study counties, we found that publicly conserved lands were significantly lower in HM than both privately conserved and random non-conserved parcels (Figs. 3 and 4, and Online Resource 7). Privately conserved parcels were not significantly different in HM than random nonconserved parcels (Fig. 5 and Online Resource 7). Publicly conserved attributes for both counties included significantly lower HM, larger parcel area, higher elevation, and a closer proximity to water than random non-conserved parcels (Online Resource 7). For privately conserved parcels, results supported a closer proximity to water, roads and publicly protected areas when compared to random non-conserved parcels (Online Resource 7). Finally, publicly conserved lands proved to be larger in area, and further from primary and secondary roads and urban areas than privately conserved parcels (Online Resource 7).

Land cover in both counties was primarily forested (Fig. 6 and Fig. 7); additionally, publicly protected lands were primarily forested. As matching of privately protected and non-conserved parcels was in part based on land cover, privately protected parcels and non-conserved matched parcels had very close proportions of land cover categories. All conserved lands had a higher proportion of forested land cover (e.g. privately protected lands Figs. 8 and 9) than does the county in general (Figs. 6 and 7). The $90 \mathrm{~m}$ buffer of privately protected lands had at least three times the developed land cover than in protected or matched parcel areas and captured less agriculture than the privately protected areas. There was considerably less land in agriculture in publicly protected areas compared to all other classes (Figs. 10 and 11).

Edge contrast (ECON) was lower in Caldwell County for both landscape and HM class analyses, with the exception of high HM. We observed edge contrast to be about the same or higher when comparing privately conserved and matched nonconserved patches. Only Rutherford County's moderate category had a significantly higher contrast in privately protected than in matched parcels. Contrast tended to increase as HM increased, with the exception being Rutherford's privately protected patches that had a moderate HM. In this case, contrast was high relative to the general contrast trends. ECON is measured as a percentage and bound between 0 and 100. In the case of either county we saw no contrast greater than approximately 25\% (Figs. 12 and 13, Online Resource 8).
Fig. 3 Privately protected parcels evaluated for significant difference in $\mathrm{HM}$ with publicly protected lands in two Appalachian counties

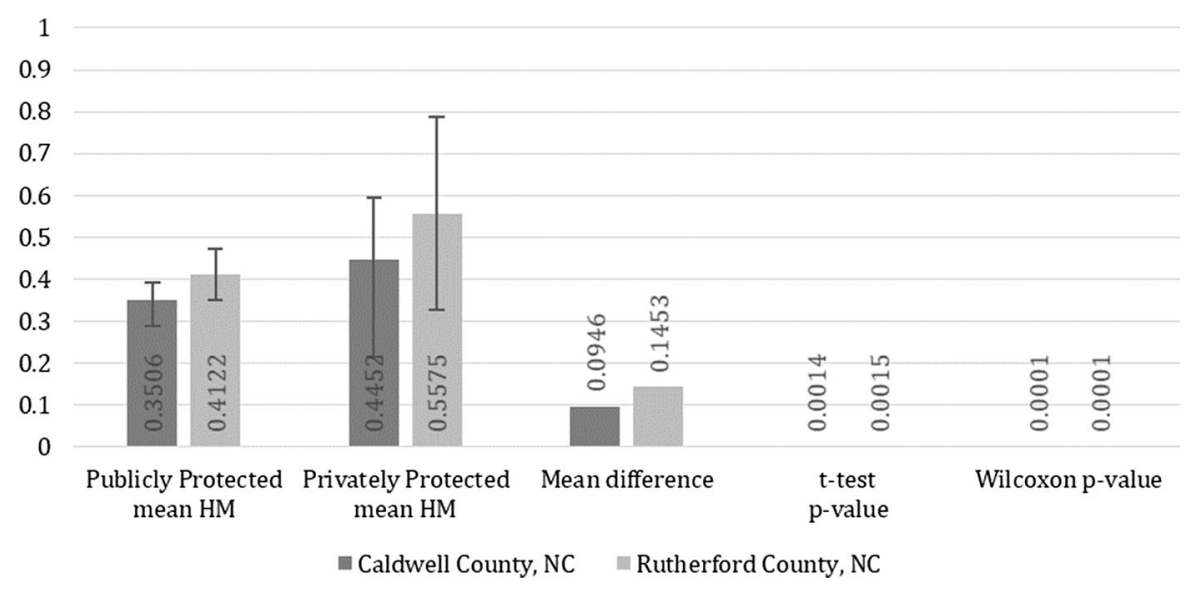




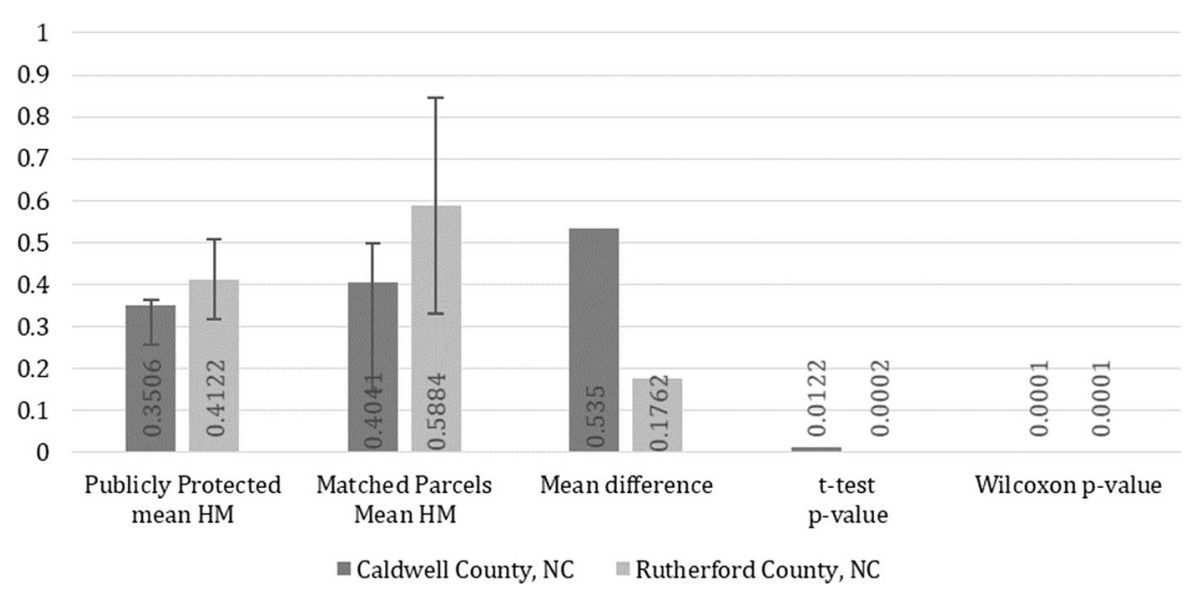

Fig. 4 Publicly protected parcels evaluated for significant difference in HM with non-protected matched parcels in two Appalachian counties

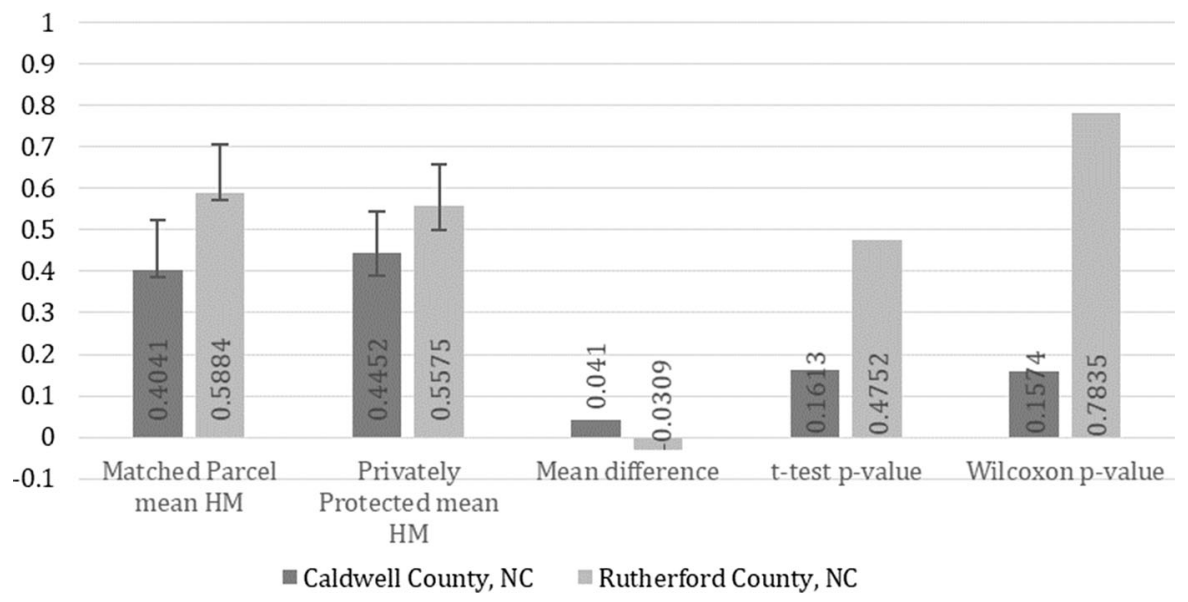

Fig. 5 Privately protected parcels evaluated for significant difference with non-protected matched parcels in two Appalachian counties

Hypothesis 3 We used k-fold cross validation resampling $(\mathrm{N}=100)$ to test for model accuracy. The MNLR models resulted in Caldwell County, NC having an overall accuracy of $81.3 \%$ (lower than our 95\% confidence requirement) and the Rutherford County, NC final model having $96.5 \%$ accuracy. The model was also checked for outliers and multicollinearity among predictors (Online Resource 3). In both counties, majority land cover and population density were shown to have a quasi-perfect separation to the HM categories and therefore were removed from analysis. The model containing all predictors utilized shows a significant contribution by all variables when added to the null model for Caldwell County, and all variables except roads and water are significant for Rutherford County (Table 1). Addition of the predictors to both the Caldwell and Rutherford County models that contained only the intercept significantly improved the fit in both counties between model and data, $\chi^{2}(16, \mathrm{~N}=237)=243.92$, McFadden's $\mathrm{R}^{2}=0.57, \quad \mathrm{p}<0.001, \quad$ and $\chi^{2} \quad(16$, $\mathrm{N}=309)=478.54, \quad$ McFadden's $\quad \mathrm{R}^{2}=0.93$, $\mathrm{p}<0.001$, respectively. The variance inflation factor (VIF) was acceptable for all variables in both counties (VIF less than 10), however it is relatively high in Rutherford County for proximity to public land, DEM, proximity to urban areas, and parcel area, suggesting the potential for some multicollinearity.

Both models were culled to exclude predictors that did not have significant unique effects in the context of the other variables in the model. All predictors for 

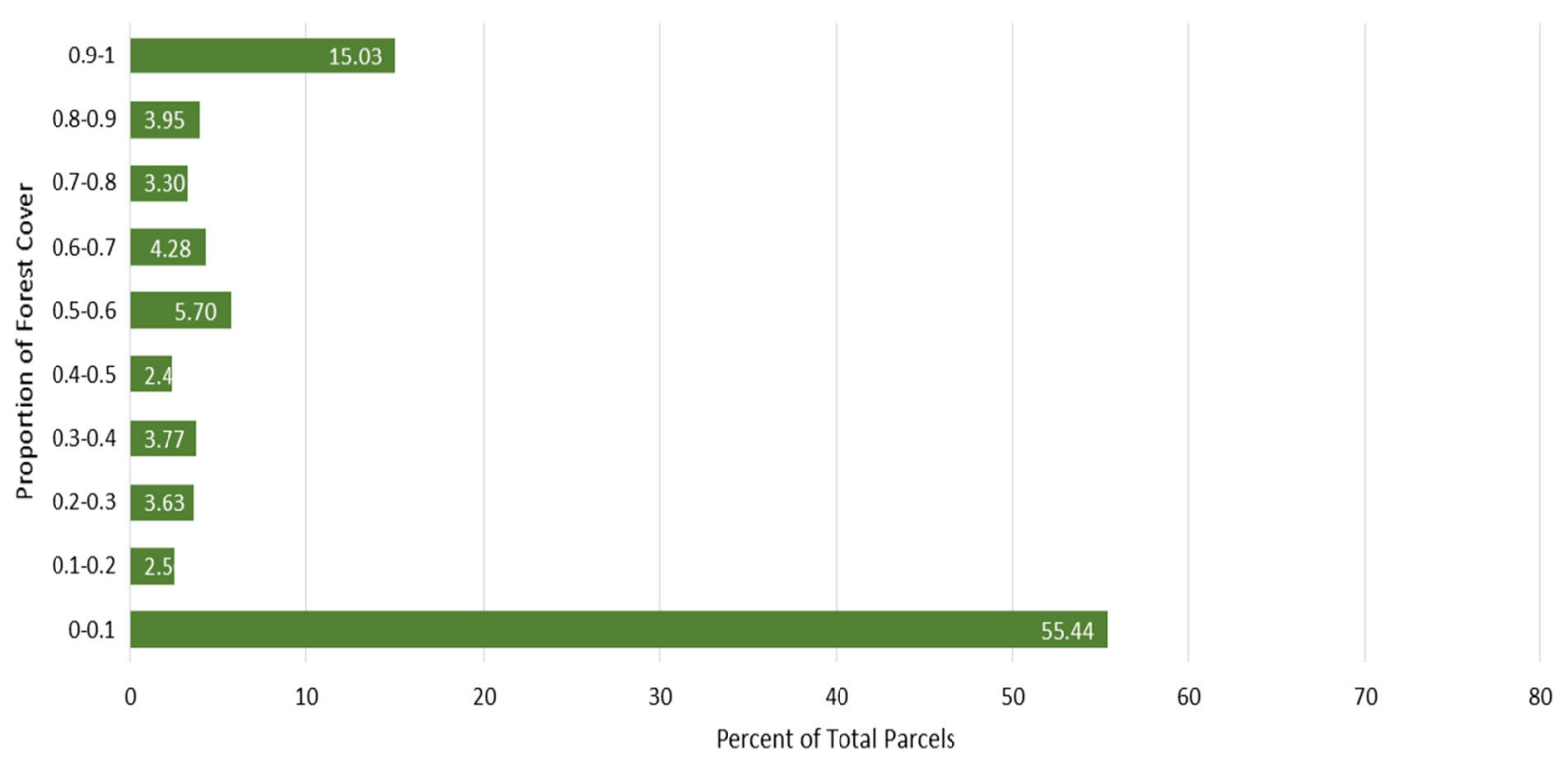

Fig. 6 Relative percentage of total parcels in Caldwell County by the proportion of forest cover
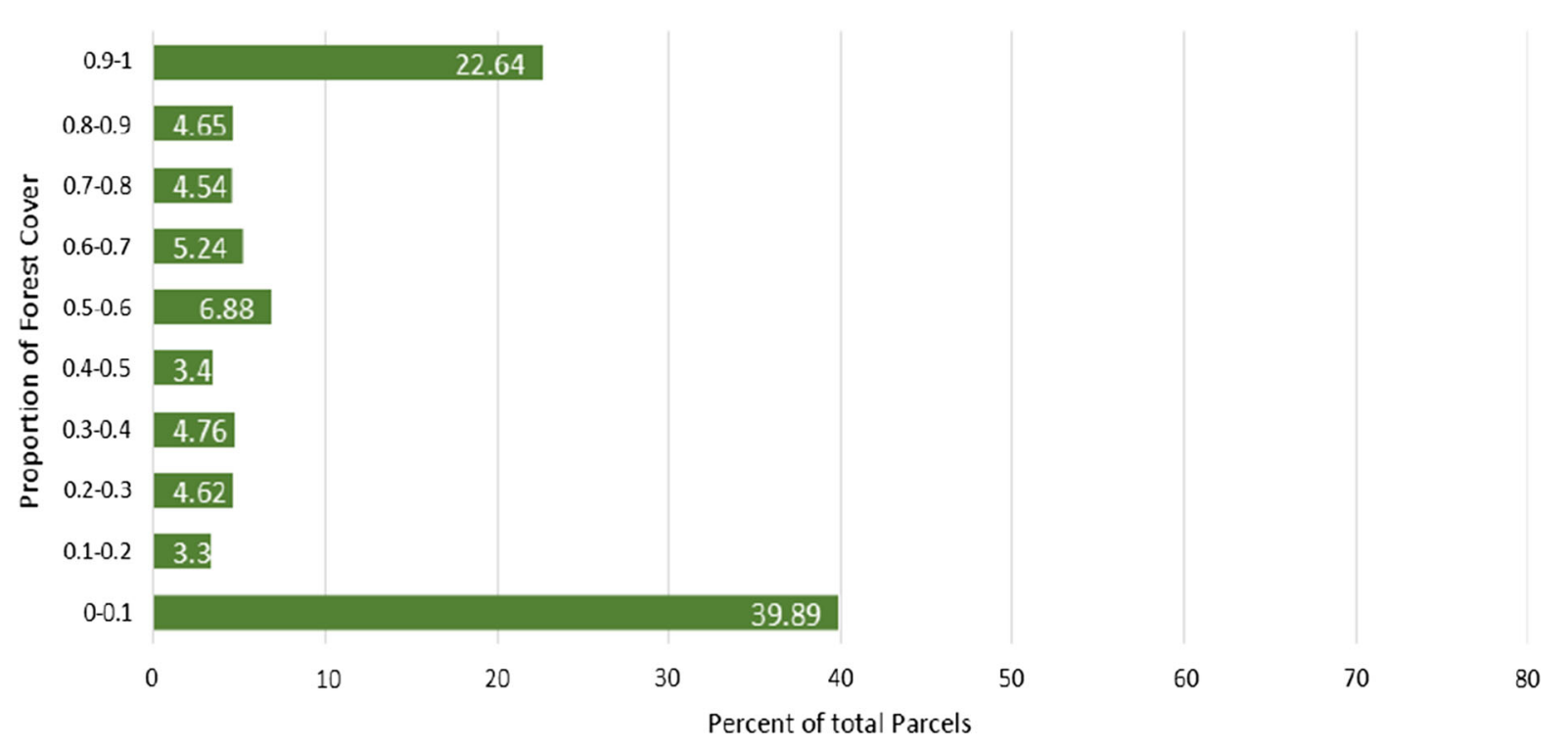

Fig. 7 Relative percentage of total parcels in Rutherford County by the proportion of forest cover

Caldwell County were significant in terms of unique contributors to the model and $\mathrm{p}$-values generated from the regression analysis. Therefore, the Caldwell model was not reduced. However, the Rutherford model included insignificant variables (roads and water) based on the $\chi^{2}$ analysis. Roads were removed and the $\chi^{2}$ rerun showing that water is significant in that reduced model and DEM is not in the context of the remaining predictors contained in the model. DEM was removed and $\chi^{2}$ rerun to ensure the rest of the variables were significant. The resulting model containing five predictors (proximity to public land, median income, proximity to urban areas, parce1 area, and proximity to water) were statistically significant $\chi^{2}(10, \mathrm{~N}=309)=475.91$, McFadden's $\mathrm{R}^{2}=0.93, \mathrm{p}<0.0001$.

A summary of the model statistics, shows that the reduced Rutherford model is very similar to the full Rutherford model and obtained a good parsimonious subset of variables including a minimized AIC (from 


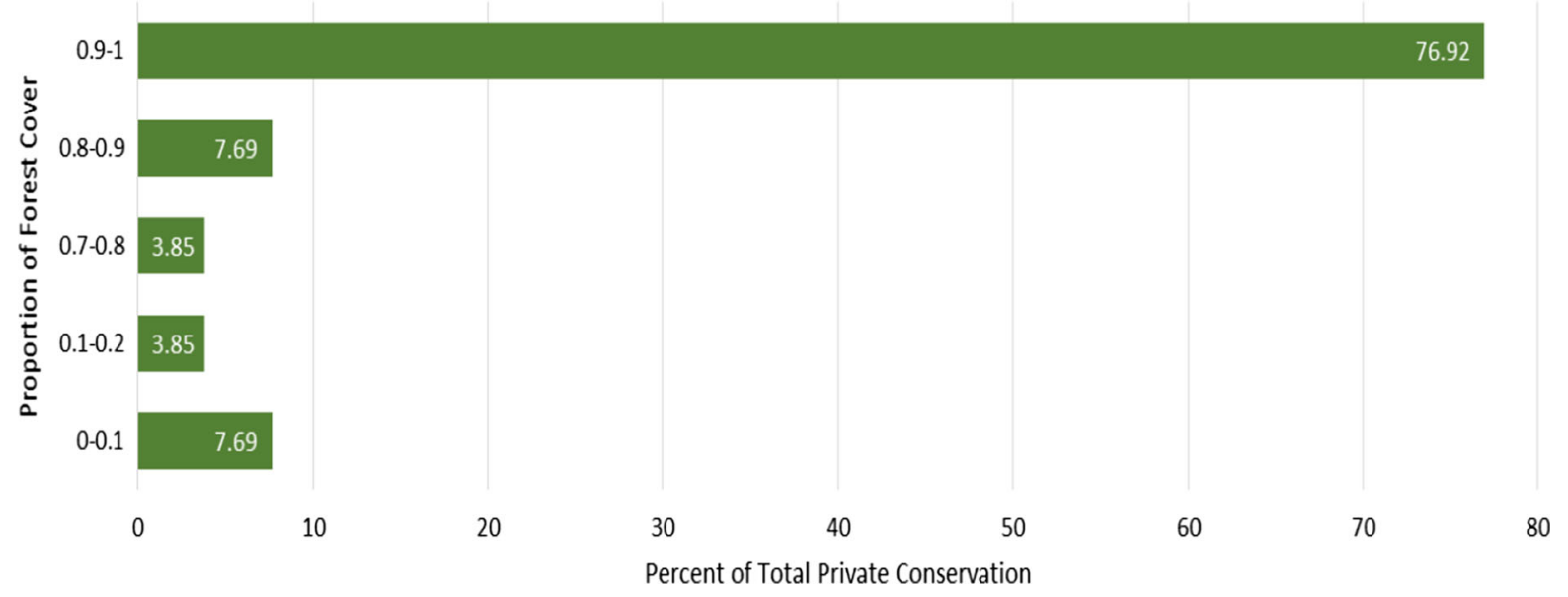

Fig. 8 Relative percentage of total private conservation properties in Caldwell County by the proportion of forest cover

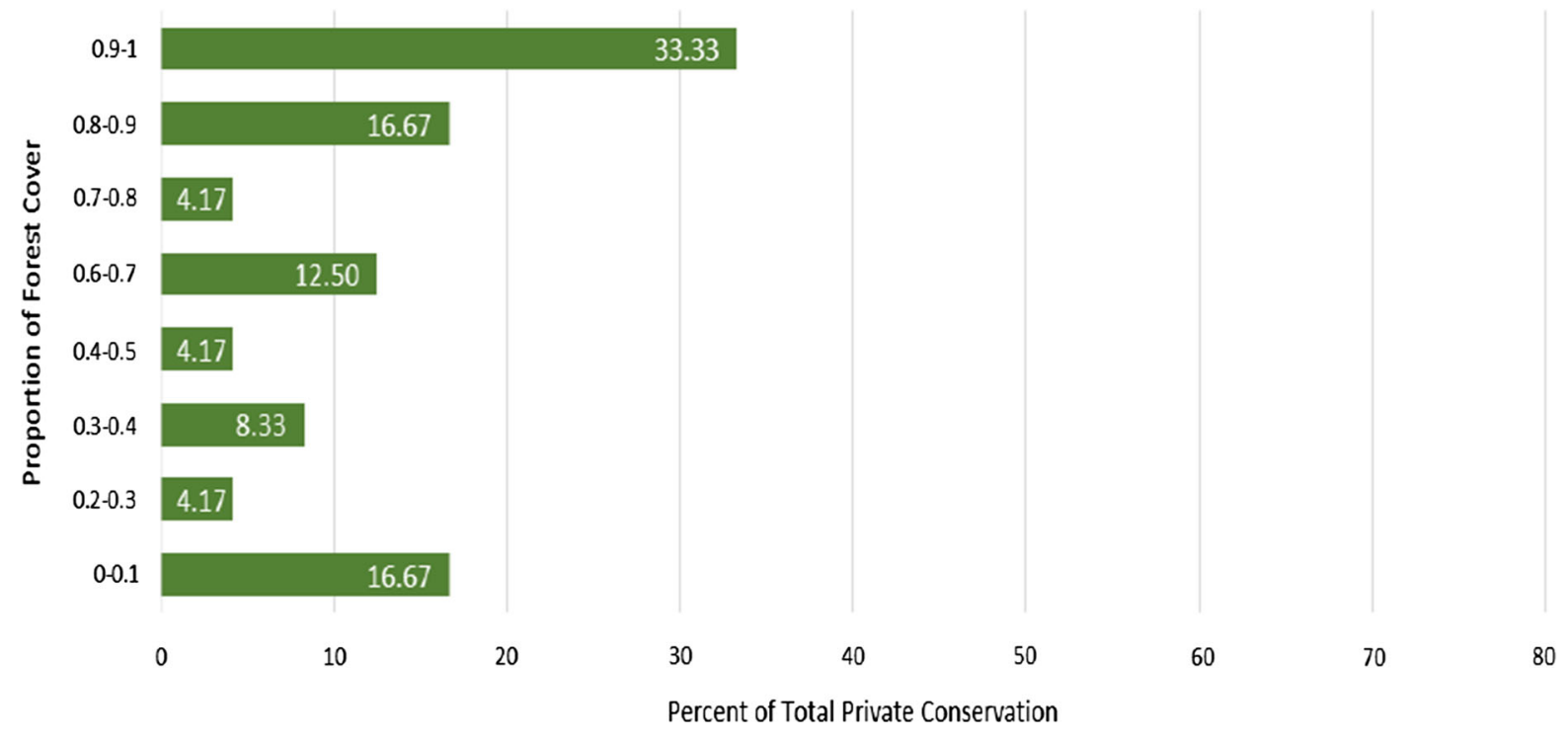

Fig. 9 Relative percentage of total private conservation properties in Rutherford County by the proportion of forest cover

full to reduced) with a minimal impact on the other overall model statistics (Table 2).

The reference group for the MNLR was HM category moderate. Accordingly, each predictor had two parameters, one for predicting membership in the high category versus moderate, and one for membership in the very high category, also versus moderate. In Caldwell County, three predictors had significant parameters for comparing moderate to high HM. For each one standard deviation increase in proximity to roads, public conservation areas, and median income, the odds of being in the high category rather than the moderate category were decreased by less than 0.006 times (Table 3). All predictors had significant parameters for comparing the moderate category to the very high HM category. For each one standard deviation increase in median income and proximity to roads and public areas and urban lands, the odds of being in the very high category rather than the moderate category were decreased by more than $0.5,0.85$, and 0.45 times, respectively (Table 3). For each one standard deviation increase in water proximity, median income and area, the odds of being in the very high category rather 
Fig. 10 Proportion of land cover for Caldwell County by NLCD category, rolled up in summary categories for visualization, and evaluated based on county, privately protected $90 \mathrm{~m}$ edge buffer, privately protected parcels, matched non-protected parcels, and publicly protected lands

Fig. 11 Proportion of land cover for Rutherford County by NLCD category, rolled up in summary categories for visualization, and evaluated based on county, privately protected $90 \mathrm{~m}$ edge buffer, privately protected parcels, matched non-protected parcels, and publicly protected lands

Fig. 12 Mean edge contrast (ECON) comparing patch types (privately protected and matched non-protected) from both a landscape level perspective and a HM category/class perspective in Caldwell County, NC
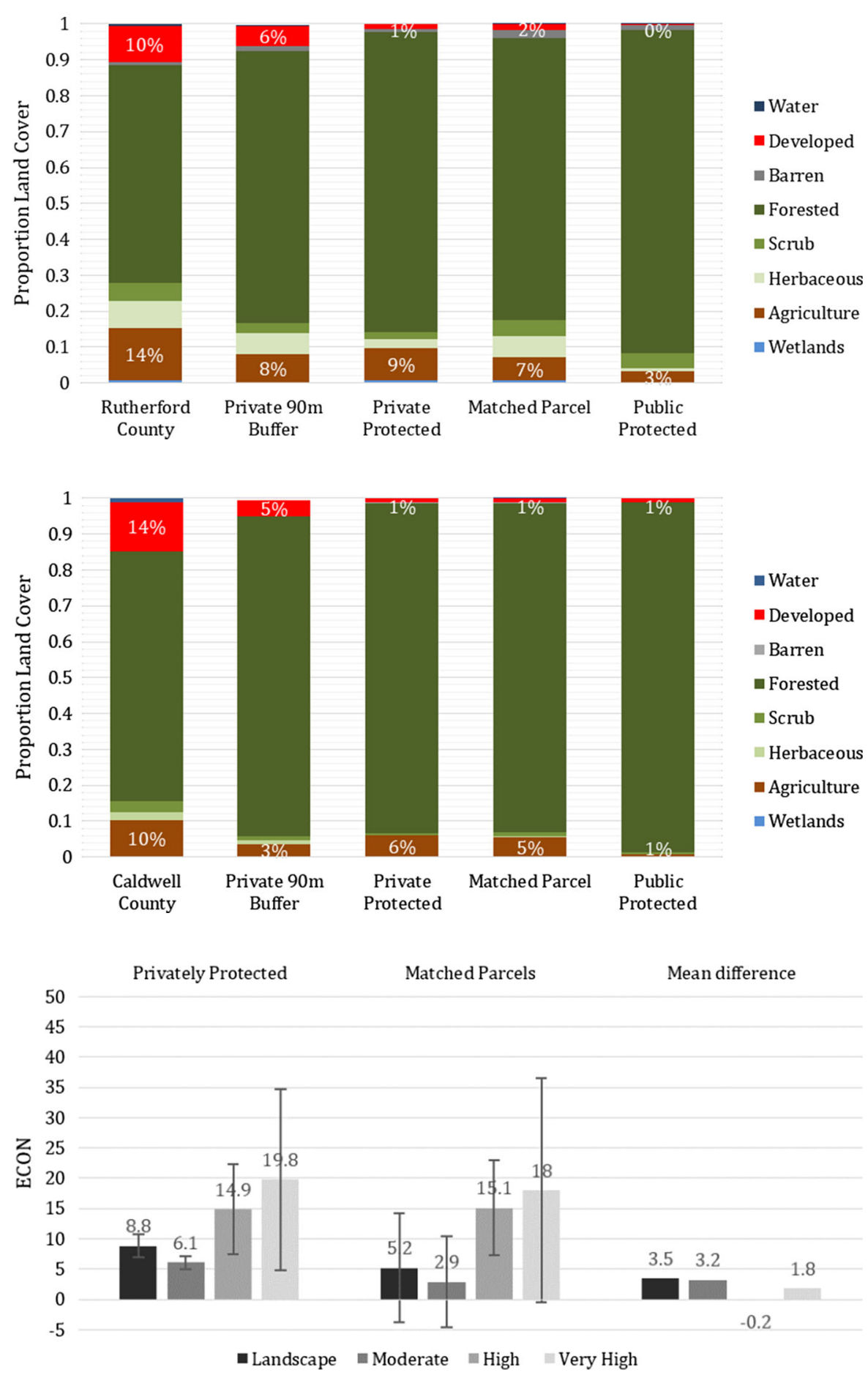

than the moderate category were increased by more than 5.5, 1.25, and 3500 times, respectively (Table 3).

The results of the intermediate (full) model for Rutherford County, NC can be found Online Resource
9. The final model for Rutherford County, contained four predictors that had significant parameters for comparing moderate to high HM. For each one standard deviation increase in median income and 


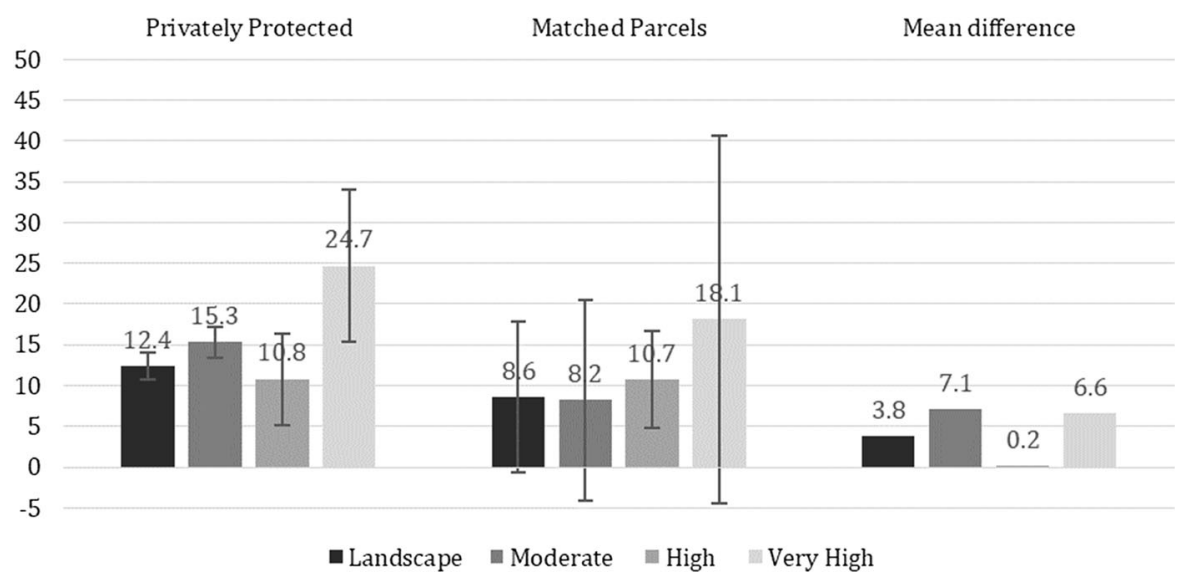

Fig. 13 Mean edge contrast (ECON) comparing patch types (privately protected and matched non-protected) from both a landscape level perspective and a HM category/class perspective in Rutherford County, NC

Table 1 Unique Contribution of Predictors of HM in both Caldwell and Rutherford County, North Carolina, where VIF is the ratio of variance of the final model to the variance of the null model

*Significant at $\alpha=0.05$

\begin{tabular}{|c|c|c|c|c|c|c|}
\hline \multirow[t]{2}{*}{ Predictors } & \multicolumn{3}{|c|}{ Caldwell County, NC $(\mathrm{N}=237)$} & \multicolumn{3}{|c|}{ Rutherford County, NC ( $\mathrm{N}=309)$} \\
\hline & $\chi^{2}$ & p-value & VIF & $\chi^{2}$ & p-value & VIF \\
\hline Road proximity & 44.02 & $<0.0001 *$ & 1.85 & & & \\
\hline Public land proximity & 58.46 & $<0.0001 *$ & 4.50 & 21.96 & $<0.0001 *$ & 5.70 \\
\hline Water proximity & 16.01 & $0.0003 *$ & 1.67 & 18.32 & 0.0001 & 1.09 \\
\hline Median income & 11.02 & $0.0041 *$ & 1.85 & 178.47 & $<0.0001^{*}$ & 2.66 \\
\hline Elevation & 7.43 & $0.0243 *$ & 3.28 & & & \\
\hline Urban area proximity & 52.64 & $<0.0001 *$ & 1.76 & 28.58 & $<0.0001^{*}$ & 7.51 \\
\hline Area & 7.16 & $0.0279 *$ & 2.70 & 46.32 & $<0.0001^{*}$ & 4.29 \\
\hline
\end{tabular}

Table 2 Statistical summaries for all multinomial logistic regression models created to evaluate Hypothesis 3, drivers of the level of HM (Moderate, High, and Very High)

\begin{tabular}{|c|c|c|c|c|c|}
\hline County, State & $\begin{array}{l}\text { Log-likelihood } \\
\text { null }\end{array}$ & $\begin{array}{l}\text { Log-likelihood } \\
\text { fitted }\end{array}$ & $\begin{array}{l}\text { McFadden's } \\
\mathrm{R}^{2}\end{array}$ & $\begin{array}{l}\text { Max likelihood } \\
\mathrm{R}^{2}\end{array}$ & AIC \\
\hline Caldwell County, NC (full model) & -206.28 & -88.82 & 0.5694 & 0.5694 & 209.64 \\
\hline Rutherford County, NC (full model) & -256.33 & -17.06 & 0.9335 & 0.7875 & 66.12 \\
\hline $\begin{array}{l}\text { Rutherford County, NC (final reduced } \\
\text { model) }\end{array}$ & -256.33 & -18.37 & 0.9283 & 0.7857 & 60.74 \\
\hline
\end{tabular}

Models include the full model for both Caldwell and Rutherford Counties, NC, and the reduced model for Rutherford County, NC

proximity to water, public lands, and urban areas, the odds of being in the high category rather than the moderate category were decreased by less than 0.01 times (Table 4). All predictors had significant parameters for comparing the moderate category to the very high HM category. For each one standard deviation increase in median income and proximity to water, public lands, and urban areas, the odds of being in the very high category rather than the moderate category were decreased by less than 0.02 times, with area decreased by more than 0.15 times (Table 4 ).

\section{Field visits}

Field visits provided contextual information to inform interpretation of HM (Online Resource 1). We found that for the purposes of verifying, HM or naturalness at a particular point, fine scale imagery 
Table 3 Contrasting parameter estimates, odds ratio, and p-value by HM category for Caldwell County, North Carolina

\begin{tabular}{|c|c|c|c|c|}
\hline Predictor & Moderate human modification (HM) versus & Estimate & Odds ratio & p-value \\
\hline \multirow[t]{2}{*}{ Road proximity } & High & -0.0058 & 0.9942 & $0.0002 *$ \\
\hline & Very high & -0.8369 & 0.4331 & $<0.0001 *$ \\
\hline \multirow[t]{2}{*}{ Public land proximity } & High & -0.0007 & 0.9993 & $<0.0001^{*}$ \\
\hline & Very high & -2.10 & 0.1222 & $<0.0001^{*}$ \\
\hline \multirow[t]{2}{*}{ Water proximity } & High & 0.0006 & 1.00 & 0.3356 \\
\hline & Very high & 1.76 & 5.82 & $<0.0001^{*}$ \\
\hline \multirow[t]{2}{*}{ Median income } & High & -0.0001 & 0.9999 & $0.0016^{*}$ \\
\hline & Very high & 0.2403 & 1.27 & $<0.0001^{*}$ \\
\hline \multirow[t]{2}{*}{ Elevation } & High & -0.0002 & 0.9998 & 0.4130 \\
\hline & Very high & -3.35 & 0.0350 & $<0.0001^{*}$ \\
\hline \multirow[t]{2}{*}{ Urban area proximity } & High & -0.00005 & 0.9999 & 0.1212 \\
\hline & Very high & -0.6674 & 0.5131 & $<0.0001^{*}$ \\
\hline \multirow[t]{2}{*}{ Area } & High & -0.00005 & 0.9999 & 0.4752 \\
\hline & Very high & 8.26 & 3863.08 & $<0.0001^{*}$ \\
\hline
\end{tabular}

*Significant at $\alpha=0.05$

Table 4 Rutherford County final multinomial logistic regression model reduced to exclude predictors of HM that did not have significant unique effects in the context of the full model

\begin{tabular}{|c|c|c|c|c|}
\hline Predictor & Moderate human modification (HM) versus & Estimate & Odds ratio & p-value \\
\hline \multirow[t]{2}{*}{ Area } & High & -0.0097 & 0.9903 & 0.1490 \\
\hline & Very High & -0.1875 & 0.8291 & $0.0113 *$ \\
\hline \multirow[t]{2}{*}{ Public land proximity } & High & -0.0014 & 0.9986 & $0.0098^{*}$ \\
\hline & Very high & -0.0016 & 0.9984 & $0.0016^{*}$ \\
\hline \multirow[t]{2}{*}{ Water proximity } & High & -0.0097 & 0.9904 & $0.0154 *$ \\
\hline & Very high & -0.0200 & 0.9802 & $0.0022 *$ \\
\hline \multirow[t]{2}{*}{ Median income } & High & -0.0008 & 0.9992 & $<0.0001^{*}$ \\
\hline & Very high & -0.0005 & 0.9995 & $0.0224 *$ \\
\hline \multirow[t]{2}{*}{ Urban area proximity } & High & -0.0033 & 0.9967 & $0.0042 *$ \\
\hline & Very high & -0.0038 & 0.9962 & $0.0015^{*}$ \\
\hline
\end{tabular}

*Significant at $\alpha=0.05$

aslo proved to be valuable. The imagery was beneficial, as it provided insight into the type of adjacent landscape features to a specific point that may be influencing the HM. In one instance the field visit revealed the composition at a privately conserved parcel sample point (Table 5). The amount of contextual information about the landscape provided by a field visit was limited by the route taken in and out to the evaluation point.
After consolidating information from the field visits, the HM layer, and Google imagery, we noted that there had been increased low-density residential development since the HM estimation was produced in 2016. HM is based on both theoretical and practical understanding of the impact from landscape e.g., roads, and although an area or point may have seemed fairly remote and natural visually (eliciting the expectation of a relatively low to moderate HM), it 
may have actually been in close proximity or in a land use that imposed heavy modification despite its natural appearance. Consequently, leveraging fine scale imagery was paramount to understanding the impact of modification on a particular point.

\section{Discussion}

Using the Human Modification estimate (HM) as a measure of landscape naturalness, we found that in a mixed-use landscape privately conserved parcels (CEs and private conservation preserves) were not significantly more natural relative to matched privately held parcels, and that public lands tended significantly toward more naturalness than privately conserved and non-conserved lands. We suggest that CEs in these counties, whose land cover is characterized by mixed forest-agriculture-exurban, are a representative sample and not biased towards areas of greater naturalness, as are the public protected areas.

Overall, the odds of finding private conservation relative to random, unprotected parcels in both counties was greater when closer to water and publicly conserved lands. This may indicate a complementary conservation function between private and publicly protected areas as suggested by Rissman and Merenlender (2008) in similarly scaled geographies, and Baldwin and Leonard (2015) and Graves et al. (2019) for CEs at the regional scale. Publicly protected areas in our study area roughly followed the global trends, being located at higher elevations and on larger parcels than random, unprotected areas and also further from primary and secondary roads and urban areas (Margules and Pressey 2000; Joppa and Pfaff 2009; Baldwin and Leonard 2015). Both counties in our study are rural and/or exurban and at least $60 \%$ of the land cover is natural (i.e. forest or grasslands). Protected areas natural land cover ranges from 80 to $90 \%$, a higher proportion of natural land cover, underlying the result for naturalness, reported above. It appears that private conservation lands are more likely to be established within the mixed-used matrix, but spatially biased to areas closer to publicly protected lands.

This study used a relatively coarse-scale metric, the $\mathrm{HM}$ at $90 \mathrm{~m}$ resolution, to assess condition composition of parcels within a relatively small geography, counties. Counties were the unit of analysis, as they have been in similar studies, because A) that is the source from which parcel data is curated and may be extracted, and B) counties and municipalities are the policy unit with land use authority, at least in the United States (Dale et al. 2000; Cullingworth 2004). There is the possibility that $90 \mathrm{~m}$ resolution data applied to parcels (average size in analysis 40 ha (Caldwell) and 50 ha (Rutherford)) is a scale mismatch, and that finer resolution naturalness data may capture differences that our approach did not. For some of our smallest parcels, the neighborhood used in the HM may have captured outside cells, which is why we examined edge contrast. Nevertheless, edge

Table 5 Percentage of field visits that revealed HM features by: no major HM feature present/HM feature revealed by both the field visit and the fine-scale imagery; HM feature revealed only by fine-scale imagery; and HM feature revealed only by field visit

\begin{tabular}{|c|c|c|c|c|c|c|}
\hline \multirow[t]{2}{*}{ County, State } & \multicolumn{2}{|c|}{$\begin{array}{l}\text { Percentage where no HM feature } \\
\text { was present/HM feature was } \\
\text { revealed by field visit and fine- } \\
\text { scale imagery }\end{array}$} & \multicolumn{2}{|c|}{$\begin{array}{l}\text { Percentage that revealed HM } \\
\text { feature in fine-scale imagery and } \\
\text { not in field visit }\end{array}$} & \multicolumn{2}{|c|}{$\begin{array}{l}\text { Percentage that revealed HM } \\
\text { feature in field visit and not in } \\
\text { fine-scale imagery }\end{array}$} \\
\hline & $\begin{array}{l}\text { Privately } \\
\text { protected }\end{array}$ & $\begin{array}{l}\text { Matched } \\
\text { parcels }\end{array}$ & $\begin{array}{l}\text { Privately } \\
\text { protected }\end{array}$ & $\begin{array}{l}\text { Matched } \\
\text { parcels }\end{array}$ & $\begin{array}{l}\text { Privately } \\
\text { protected }\end{array}$ & $\begin{array}{l}\text { Matched } \\
\text { parcels }\end{array}$ \\
\hline Caldwell County, NC & 9 of $15(60 \%)$ & $\begin{array}{c}10 \text { of } 11 \\
(91 \%)\end{array}$ & 5 of $15(33 \%)$ & 1 of $11(9 \%)$ & 1 of $15(6 \%)$ & 0 of $11(0 \%)$ \\
\hline $\begin{array}{l}\text { Rutherford County, } \\
\text { NC }\end{array}$ & 12 of $15(80 \%)$ & $\begin{array}{c}13 \text { of } 15 \\
(86 \%)\end{array}$ & 3 of $15(20 \%)$ & 2 of $15(13 \%)$ & 0 of $15(0 \%)$ & 0 of $15(0 \%)$ \\
\hline
\end{tabular}

Caldwell matched parcels contained only 11 field points instead of 15 because only one field point was available for the Very High HM category 
contrast results lead to a similar inference as did the matched-pairs results. Also, field visits suggested that the HM estimate realistically represented the land cover we observed, at least at the scale measured. However, remote measures such as the degree of HM do not capture many aspects of human impact such as land use legacies, which may be obscured, at least in this region, by forest regenerated over former agricultural areas (Richter et al. 2000; Foster et al. 2003).

The sample design was constructed to maximize spatial autocorrelation, and size and land cover similarities across pairs. As a result, differences should be attributed to the treatment, whether or not the private parcel is conserved. To this end, we see that privately conserved parcels show no difference from matched parcels in naturalness given they are approximately the same size and land cover, with no detected difference in proximity to urban areas, and a closer proximity to primary and secondary roads. Our results are best viewed as a case study involving two counties representing a mixed use matrix, and may be transferrable to similar geographies. They should be tested in other landscapes, including where there are sharper urban-rural gradients, and different geographical contexts (e.g., rangelands).

When we considered ordinal categories of $\mathrm{HM}$ as a dependent variable, results did not strongly depart from the matched pairs approach in that there were no strong spatial drivers of increases in naturalness. Three predictors in the multinomial regression had significant parameters for comparing the moderate category with the high HM category in Caldwell County. For each one standard deviation increase in proximity to roads and publicly protected areas, and median income, the odds of being in the moderate category rather than the high category were all slightly less than one. This suggests that odds are only slightly more likely to be in the moderate category given an increase in any of the significant predictors. All predictors had significant parameters for comparing the moderate category to the very high HM category, however, odds ratios ranged from less than one to far greater than one. Given an increase in some predictors (proximity to roads, public conservation, and urban areas, and higher elevation) odds of the HM being found in the very high category were at least $40 \%$ less than the odds of HM in the moderate category. Given an increase in other predictors (proximity to water, parcel area, and median income) there was an associated increase in odds in HM in the very high category, ranging from approximately 1.27 times higher for median income, almost 5.5 times higher for proximity to water, and more than 3500 times higher for a larger parcel area. In Rutherford County, all predictors for both the high and very high categories were significant and odds ratios were all slightly lower than one, suggesting an increase in those predictors likely only mildly increased the odds outcome toward the reference category (moderate). Of note, median income played a notable role, suggesting that consideration of social/ demographic variables may help to explain HM, and could be explored in future studies.

The census boundary used in this analysis was the block group; it is more likely to have available data in rural and exurban areas than the finer block level data, and provides more heterogeneity than the coarser census tract data. There is the potential for this scale effect to be relevant to assess parcel-level features. The potential scale effect poses concerns as features can be lost or distorted with different grain definitions (Turner et al. 1989), and coarser scale measures that drive $\mathrm{HM}$ in landscape may be poor predictors of changes occurring at finer scales (Wear and Bolstad 1998). Understanding grain and other scale effects using ecological measurement provides insight for correcting potential information loss across changing spatial scales (Turner et al. 1989).

Our study underscores weaknesses in how spatial data on conservation easements are curated (Olmsted 2011). We found the National Conservation Easement Database (NCED) and the list of conservation properties obtained from FCNC were mutually exclusive. NCED has omissions, and local conservancy data is specific to only their holdings. In a concurrent study in which we are gathering county level data across the Nation, we have discovered similar spatial omissions. These problems are not unique to our study, as biogeographic and socio-geographic data are continually updated and re-released and any study using them should acknowledge version and date, and metadata should cover potential omissions (Jenkins et al. 2015). Researchers can, as we did, attempt to make or supplement updated and composite datasets when applicable given scale and purpose of analysis, and not rely solely on publicly available sources.

Lastly, estimations, indices, and scores of naturalness or ecological integrity are especially difficult to validate due to variation in definition, purpose, and 
assumptions, and due to the qualitative nature of the concept (McGarigal et al. 2018). As others have done, we accepted the limits of remotely-sensed measures of integrity in order to make inference about phenomena at the landscape scale (Venter et al. 2016). We used a single metric rather than conduct a comparative study using a range of available metrics due to the complexity of the analyses we undertook. Few studies exist that systematically compare maps of estimates of human influence on natural systems. But those that have been done reveal differences in estimation of HM based on model structure and formulation. The HM estimate we used differs at the global scale from the global degree of HM in how the degree of modification is measured at the lower ends of the scale, and by ecoregion (Oakleaf and Kennedy 2018; Kennedy et al. 2019), but no studies of which we are aware have used multiple metrics to measure the same phenomenon as in composition and condition of protected areas or easements. Therefore, we suggest that future research attempting to use remotely-based measures of naturalness or integrity to assess composition or condition of conservation easements do so using a range of metrics including HM, HF, Index of Ecological Integrity, and InVEST biodiversity habitat value (Nelson et al. 2009; McGarigal et al. 2018). Finally, all of these metrics are based on remotely-sensed and classified land use land cover data at relatively coarse scales, and may, as mentioned earlier, miss aspects of ecosystem function which may be rectified by finer scale imagery and those that have been systematically verified at local scales such as Global Land Use Emergent Database (GLUED) (Theobald 2016).

Our purpose was to examine how naturalness across two southern Appalachian counties may be used to assess conservation contributions of relatively small conserved features, specifically conservation easements. We found that in mixed use landscapes, contrary to our expectation, CEs may not be biased towards greater naturalness. They may represent the existing landscape, and reflect conservation values of local conservationists and landowners. Conserving open space and agricultural land is a valid basis for an establishment of CEs and may be implemented where that is the dominant land use, rather than seeking properties representing the most natural end of the gradient. Baldwin and Leonard (2015) found that in more remote parts of this region, larger easements and those owned by large NGOs may be more likely to be adjacent to existing protected areas, and the greatest quantity of easements are likely to be closer to human settlement.

Given mismatches in conservation priorities and distribution of public protected areas, alternative conservation mechanisms must be explored, evaluated, and improved. Regardless of the conservation instrument employed, the naturalness generated over time and across space of private projects relative to publicly protected areas is a subject for landscapelevel analysis to better understand how and where conservation goals are achieved. We found that studying the HM using paired sampling differences and parcel-level predictors provides insight into the composition and function of easements. We hypothesize that in landscapes with sharper wildland-ruralurban gradients, there will be differences in composition between easements and non-conserved parcels, and that easements will contribute to matrix permeability. We need to better understand trends of the naturalness both prior to, and following private conservation across more diverse geographic contexts.

\section{Conclusion}

We examined the composition of naturalness and social variables within a mixed-use matrix of privately conserved parcels and private non-conserved parcels in two Appalachian counties. Generally, we found that publicly protected lands had a significantly lower level of HM than privately conserved and non-conserved lands, and that there was no significant difference in the level of HM between privately conserved and random non-conserved parcels. We found that privately conserved parcels were physically closer to publicly conserved areas, water, and primary and secondary roads, compared to non-conserved parcels. Given the variables (Online Resource 3), and using the moderate HM category as our reference, we found that the odds of being in the moderate category were increased relative to both categories (high, very high) in Rutherford County and for the high category in Caldwell County. When evaluating the odds of being 
in the moderate $\mathrm{HM}$ category relative to the very high category given the same predictors in Caldwell County, we found that with one increase in standard deviation there is an increase in odds toward the very high HM category for median income, the proximity to water, and the area of the parcel. This assessment contributes to a growing body of work on the function, composition, and conservation benefit derived from conservation easements. Specifically, we use these methods and results to help inform conservation and land-use planning through trends in the level of HM found in CEs. Given incongruities in public conservation priorities and distribution and the establishment of private conservation alternatives, new and unconventional conservation instruments must be assessed and improved to better understand how and where conservation goals are achieved. The application of the HM estimate creates a way to empirically assess the conservation value of the conserved lands, and its application on these parcels may affirm the land trusts mission for these properties and provide examples where conservation value may be the by-product of CE placement rather than the objective.

Acknowledgements Financial support was provided by the National Science Foundation (NSF) and The Margaret $\mathrm{H}$. Lloyd-SmartState Endowment at Clemson University. Foothills Conservancy of North Carolina (FCNC) provided data in addition to access to conservation properties for field study. Special thanks goes to A. Kota, Executive Director of FCNC, and to R. Sparks, Conservation Associate, for providing access to data and coordinating field visits. The authors are also grateful to M. Laura, P. Leonard, and D. White, for guidance.

Open Access This article is distributed under the terms of the Creative Commons Attribution 4.0 International License (http:// creativecommons.org/licenses/by/4.0/), which permits unrestricted use, distribution, and reproduction in any medium, provided you give appropriate credit to the original author(s) and the source, provide a link to the Creative Commons license, and indicate if changes were made.

\section{References}

Angermeier PL (2000) The natural imperative for biological conservation. Conserv Biol 14:373-381

Baldwin RF, Demaynadier PG (2009) Assessing threats to poolbreeding amphibian habitat in an urbanizing landscape. Biol Conserv 142:1628-1638

Baldwin RF, Leonard PB (2015) Interacting social and environmental predictors for the spatial distribution of conservation lands. PLoS ONE 10:0140540
Borra S, Di Ciaccio A (2010) Measuring the prediction error. A comparison of cross-validation, bootstrap and covariance penalty methods. Comput Statist Data Anal 54:2976-2989

Clements HS, Selinske MH, Arcibald CL, Cooke B, Fitzsimons JA, Groce JE, Torabi N, Hardy MJ (2018) Fairness and transparency are required for the inclusion of privately protected areas in publicly accessible conservation databases. Land 7:96

Cole DN, Landres PB (1996) Threats to wilderness ecosystems: impacts and research needs. Ecol Appl 6:168-184

Corbitt DL, North Carolina Division of Archives and History (1950) The formation of the North Carolina counties, 1663-1943. Division of Archives and History, North Carolina Department of Cultural Resources, Raleigh

Cullingworth B (2004) Planning in the USA: policies, issues and processes. Routledge, London

Dale VH, Brown S, Haeuber RA, Hobbs NT, Huntly N, Naiman RJ, Riebsame WE, Turner MG, Valone TJ (2000) Ecological principles and guidelines for managing the use of

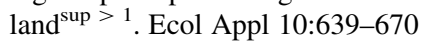

Daniels T (1999) When city and country collide. Island, Washington, DC

DeFries RS, Foley JA, Asner GP (2004) Land-use choices: balancing human needs and ecosystem function. Front Ecol Environ 2:249-257

Durand ED, Harris WJ, Hunt WC, Coulter JL, Teele RP, Steuart WM, Hourwich IA (1913) Thirteenth census of the united states taken in the year 1910: agriculture, 1909 and 1910: general report and analysis. US Government Printing Office, Washington, DC

Foothills Conservancy of North Carolina (2018) Foothills Conservancy of North Carolina. foothillsconservancy.org. Accessed 26 March 2018

Forman RT, Alexander LE (1998) Roads and their major ecological effects. Annu Rev Ecol Syst 29:207-231

Foster D, Swanson F, Aber J, Burke I, Brokaw N, Tilman D, Knapp A (2003) The importance of land-use legacies to ecology and conservation. BioScience 53:77-88

Gardner RH, Milne BT, Turnei MG, O’Neill RV (1987) Neutral models for the analysis of broad-scale landscape pattern. Landsc Ecol 1:19-28

Gardner RH, Urban DL (2007) Neutral models for testing landscape hypotheses. Landsc Ecol 22:15-29

Gaston KJ, Charman K, Jackson SF, Armsworth PR, Bonn A, Briers RA, Callaghan CSQ, Catchpole R, Hopkins J, Junine WE, Latham J, Opdam P, Stoneman R, Stroud DA, Tratt R (2006) The ecological effectiveness of protected areas: the United Kingdom. Biol Conserv 132:76-87

Gesch D, Oimoen M, Greenlee S, Nelson C, Steuck M, Tyler D (2002) The national elevation dataset. Photogramm Eng Remote Sens 68:5

Graves RA, Williamson MA, Belote RT, Brandt JS (2019) Quantifying the contribution of conservation easements to large-landscape conservation. Biol Conserv 232:83-96

Groves CR, Jensen DB, Valutis LL, Redford KH, Shaffer ML, Scott JM, Baumgartner JV, HIggins JV, Beck MW, Anderson MG (2002) Planning for biodiversity conservation: putting conservation science into practice. Bioscience 52:499-512

Gustanski JA, Squires RH (2000) Protecting the land: conservation easements past, present, and future. Island Press, Washington, DC 
Hajkowicz S, Collins K (2007) A review of multiple criteria analysis for water resource planning and management. Water Resour Manag 21:1553-1566

Hannah L, Carr JL, Lankerani A (1995) Human disturbance and natural habitat: a biome level analysis of a global data set. Biodivers Conserv 4:128-155

Harmon M, Bratton S, White P (1984) Disturbance and vegetation response in relation to environmental gradients in the Great Smoky Mountains. Vegetatio 55:129-139

Hensher DA, Stopher PR (1979) Behavioural travel modelling. Taylor \& Francis, Boca Raton

Hilty JA, Lidicker WZ, Merenlender AM (2006) Corridor ecology: the science and practice of linking landscapes for biodiversity conservation. Island Press, Washington, DC

Homer C, Dewitz J, Yang L, Jin S, Danielson P, Xian G, Coulston J, Herold N, Wickham J, Megown K (2015) Completion of the 2011 National Land Cover Database for the conterminous United States-representing a decade of land cover change information. Photogramm Eng Remote Sens 81:345

Hunter M Jr (1996) Benchmarks for managing ecosystems: are human activities natural? Conserv Biol 10:695-697

Iftekhar M, Tisdell J, Gilfedder L (2014) Private lands for biodiversity conservation: review of conservation covenanting programs in Tasmania. Aust Biol Conserv 169:176-184

Jenkins CN, Van Houtan KS, Pimm SL, Sexton JO (2015) US protected lands mismatch biodiversity priorities. Proc Natl Acad Sci USA 112:5081-5086

Jennings MD (2000) Gap analysis: concepts, methods, and recent results. Landscape Ecol 15:5-20

Joppa LN, Pfaff A (2009) High and far: biases in the location of protected areas. PLoS ONE 4:e8273

Joppa LN, Pfaff A (2011) Global protected area impacts. Proc R Soc London B 278:1633-1638

Kabii T, Horwitz P (2006) A review of landholder motivations and determinants for participation in conservation covenanting programmes. Environ Conserv 33:11-20

Kennedy CM, Oakleaf JR, Theobald DM, Baruch-Mordo S, Kiesecker J (2019) Managing the middle: a shift in conservation priorities based on the global human modification gradient. Global Change Biol 25:811-826

Kiesecker JM, Comendant T, Grandmason T, Gray E, Hall C, Hilsenbeck R, Kareiva P, Lozier L, Naehu P, Rissman A, Shaw MR, Zankel M (2007) Conservation easements in context: a quantitative analysis of their use by The Nature Conservancy. Front Ecol Environ 5:125-130

Korngold G (2006) Resolving the intergenerational conflicts of real property law: preserving free markets and personal autonomy for future generations. Am Univ Law Rev 56:1525-1582

Kutner MH, Nachtsheim CJ, Neter J, Li W (2005) Applied linear statistical models. McGraw-Hill, New York

Land Trust Alliance (2015) National land trust census. Land Trust Alliance, Washington, DC

Leu M, Hanser SE, Knick ST (2008) The human footprint in the west: a large-scale analysis of anthropogenic impacts. Ecol Appl 18:1119-1139

Machado A (2004) An index of naturalness. J Nat Conserv 12:95-110

Margules CR, Pressey RL (2000) Systematic conservation planning. Nature 405:243-253
McGarigal K, Compton BW, Plunkett EB, DeLuca WV, Grand J, Ene E, Jackson SD (2018) A landscape index of ecological integrity to inform landscape conservation. Landscape Ecol 33:1029-1048. https://doi.org/10.1007/s10980018-0653-9

McGarigal K, Cushman S, Ene E (2012) FRAGSTATS v4: spatial pattern analysis program for categorical and continuous maps. University of Massachusetts, Amherst

McLaughlin NA, Machlis MB (2008) Protecting the public interest and investment in conservation: a response to professor Korngold's Critique of Conservation Easements. Utah L Rev 1561-1594

McLaughlin NA, Weeks WW (2009) Defense of conservation easements: a response to the end of perpetuity. Wyo L Rev 9:1

Merenlender AM, Huntsinger L, Guthey G, Fairfax SK (2004) Land trusts and conservation easements: who is conserving what for whom? Conserv Biol 18:65-75

Miller JR, Hobbs NT (2000) Recreational trails, human activity, and nest predation in lowland riparian areas. Landsc Urb Plan 50:227-236

Nelson E, Mendoza G, Regetz J, Polasky S, Tallis H, Cameron DR, Chan KM, Daily GC, Goldstein J, Kareiva PM, Lonsdorf E, Naidoo R, Ricketts TH, Shaw MR (2009) Modeling multiple ecosystem services, biodiversity conservation, commodity production, and tradeoffs at landscape scales. Front Ecol Environ 7:4-11

Nolte C (2018) Buying forests for conservation: contours of a global trend. Curr Opin Environ Sustain 32:68-75

Oakleaf JR, Kennedy CM (2018) Comparison of global human modification and human footprint maps. Conservation gateway, The nature conservancy. Available at: http:// www.conservationgateway.org/ConservationPractices/lands/ science/publications/Documents/HM_HF_comparison_doc umentation.pdf

Olmsted JL (2011) The invisible forest: conservation easement databases and the end of the clandestine conservation of natural lands. Law Contemp Probl 74:51-82

Parrish JD, Braun DP, Unnasch RS (2003) Are we conserving what we say we are? Measuring ecological integrity within protected areas. Bioscience 53:851-860

Porter-Bolland L, Ellis EA, Guariguata MR, Ruiz-Mallén I, Negrete-Yankelevich S, Reyes-García V (2012) Community managed forests and forest protected areas: an assessment of their conservation effectiveness across the tropics. For Ecol Manag 268:6-17

Randolph J (2012) Environmental land use planning and management, 2nd edn. Island Press, Washington, DC

Reed SE, Merenlender AM (2008) Quiet, nonconsumptive recreation reduces protected area effectiveness. Conserv Lett 1:146-154

Richter DD, Markewitz D, Heine PR, Jin V, Raikes J, Tian K, Wells CG (2000) Legacies of agriculture and forest regrowth in the nitrogen of old-field soils. For Ecol Manag 138:233-248

Riitters KH, Wickham JD, Wade TG (2009) An indicator of forest dynamics using a shifting landscape mosaic. Ecol Ind 9:107-117

Rissman AR, Lozier L, Comendant T, Kareiva P, Kiesecker JM, Shaw MR, Merenlender AM (2007) Conservation easements: biodiversity protection and private use. Conserv Biol 21:709-718 
Rissman AR, Merenlender AM (2008) The conservation contributions of conservation easements: analysis of the San Francisco Bay area protected lands spatial database. Ecol Soc 13:40

Rissman AR, Owley J, L'Roe AW, Morris AW, Wardropper CB (2017) Public access to spatial data on private-land conservation. Ecol Soc 22:24

Sanderson EW, Jaiteh M, Levy MA, Redford KH, Wannebo AV, Woolmer G (2002) The human footprint and the last of the wild: the human footprint is a global map of human influence on the land surface, which suggests that human beings are stewards of nature, whether we like it or not. Bioscience 52:891-904

Schwab JA (2002) Multinomial logistic regression: basic relationships and complete problems Austin. University of Texas, Texas

Theobald DM (2003) Targeting conservation action through assessment of protection and exurban threats. Conserv Biol 17:1624-1637

Theobald DM (2004) Placing exurban land-use change in a human modification framework. Front Ecol Environ 2:139-144

Theobald DM (2005) Landscape patterns of exurban growth in the USA from 1980 to 2020. Ecol Soc 10:32

Theobald DM (2010) Estimating natural landscape changes from 1992 to 2030 in the conterminous US. Landscape Ecol 25:999-1011

Theobald DM (2013) A general model to quantify ecological integrity for landscape assessments and US application. Landscape Ecol 28:1859-1874

Theobald DM (2016) A general-purpose spatial survey design for collaborative science and monitoring of global environmental change: the global grid. Remote Sens 8:813
Theobald DM, Miller JR, Hobbs NT (1997) Estimating the cumulative effects of development on wildlife habitat. Landsc Urb Plan 39:25-36

Turner MG, O’Neill RV, Gardner RH, Milne BT (1989) Effects of changing spatial scale on the analysis of landscape pattern. Landscape Ecol 3:153-162

2012 census of agriculture vol. 1, Geographic area series. North Carolina, state and county data (2014). [Washington, D.C.] : United States Department of Agriculture, National Agricultural Statistics Service, 2014

Venter O, Sanderson EW, Magrach A, Allan JR, Beher J, Jones KR, Possingham HP, Laurance WF, Wood P, Fekete BM, Levy MA, Watson JEM (2016) Sixteen years of change in the global terrestrial human footprint and implications for biodiversity conservation. Nat Commun 7:12558

Wear DN, Bolstad P (1998) Land-use changes in southern Appalachian landscapes: spatial analysis and forecast evaluation. Ecosystems 1:575-594

Woolmer G, Trombulak SC, Ray JC, Doran PJ, Anderson MG, Baldwin RF, Morgan A, Sanderson EW (2008) Rescaling the human footprint: a tool for conservation planning at an ecoregional scale. Landsc Urb Plan 87:42-53

Yarnell SL (1998) The southern Appalachians: a history of the landscape. Diane Publishing, Collingdale

Zeller KA, McGarigal K, Whiteley AR (2012) Estimating landscape resistance to movement: a review. Landscape Ecol 27:777-797

Publisher's Note Springer Nature remains neutral with regard to jurisdictional claims in published maps and institutional affiliations. 